\title{
A preliminary study on Belousov-Zhabotinsky (BZ) reaction for consideration of basic chemical reaction in origin of life
}

\author{
Naoko Ueno ${ }^{1}$, Hiromasa Goto ${ }^{1,2, *}$ \\ ${ }^{1}$ College of Engineering Sciences, University of Tsukuba, Tsukuba, Ibaraki, 305-8573, Japan \\ ${ }^{2}$ Division of Materials Science, Faculty of Pure and Applied Sciences, University of Tsukuba, \\ Tsukuba, Ibaraki, 305-8573, Japan \\ *E-mail address: gotoh@ims.tsukuba.ac.jp
}

\begin{abstract}
Life involves many nonlinear phenomena. Non-linear chemical reactions can be a model for biological reactions. In the present research, we examine optical change of $\mathrm{BZ}$ reaction, and confirmed discharge of $\mathrm{CO}_{2}$.
\end{abstract}

Keywords: BZ reaction; oscillating reaction; redox

\section{INTRODUCTION}

$\mathrm{BZ}$ reaction is the one of the models of nonlinear phenomena [1]. BZ reaction has been known as oscillating reaction. The colour of the solution changes red to blue periodically. The process of $\mathrm{BZ}$ reaction is as follows.

$$
\begin{array}{ll}
\text { 1. } & \mathrm{BrO}^{3-}+\mathrm{Br}^{-}+2 \mathrm{H}^{+} \rightarrow \mathrm{HBrO}_{2}+\mathrm{HOBr} \\
\text { 2. } & \mathrm{HBrO}_{2}+\mathrm{Br}^{-}+\mathrm{H}^{+} \rightarrow 2 \mathrm{HOBr} \\
\text { 3. } & \mathrm{BrO}^{3-}+\mathrm{HBrO}_{2}+\mathrm{H}^{+} \rightarrow 2 \mathrm{BrO}_{2}+\mathrm{H}_{2} \mathrm{O} \\
\text { 4. } & 2 \mathrm{BrO}_{2}+\mathrm{Fe}^{2+}+\mathrm{H}^{+} \rightarrow \mathrm{HBrO}_{2}+\mathrm{Fe}^{3+} \\
\text { 5. } & 2 \mathrm{HBrO}_{2} \rightarrow \mathrm{BrO}^{3-}+\mathrm{HOBr}+\mathrm{H}^{+} \\
\text {6. } & \mathrm{CH}_{2}(\mathrm{COOH})_{2}+2 \mathrm{HOBr} \rightarrow \mathrm{BrCH}(\mathrm{COOH})_{2}+2 \mathrm{H}_{2} \mathrm{O} \\
\text { 7. } & 4 \mathrm{Fe}^{3+}+\mathrm{BrCH}(\mathrm{COOH})_{2}+\mathrm{H}_{2} \mathrm{O}+\mathrm{HOBr} \rightarrow 2 \mathrm{Br}^{-}+4 \mathrm{Fe}^{2+}+3 \mathrm{CO}_{2}+6 \mathrm{H}^{+}
\end{array}
$$

The colour of the solution is changed through redox of iron ion in the solution. The reaction proceeds periodically with the colour change through repeating the reaction of 1-7. The $\mathrm{BZ}$ reaction is based on redox reaction of $\left[\mathrm{Fe}(\mathrm{phen})_{3}\right]^{2+}$ (ferroin). 


\section{EXPERIMENTS}

\section{1. $B Z$ reaction}

$\mathrm{H}_{2} \mathrm{SO}_{4}(0.85 \mathrm{~mL})$ was added to water $(50 \mathrm{ml})$, and then $\mathrm{NaBrO}_{3}(1.1 \mathrm{~g}), \mathrm{CH}_{2}(\mathrm{COOH})_{2}$ $(0.51 \mathrm{~g})$ and $\mathrm{NaBr}(0.15 \mathrm{~g})$ were added to the solution and stirred. After the mixture turned to be colourless, $\left[\mathrm{Fe}(\mathrm{phen})_{3}\right]^{2+}$ was added dropwise to the stirring mixture. Colour change of the reaction was visually confirmed, as shown in Figure 1.

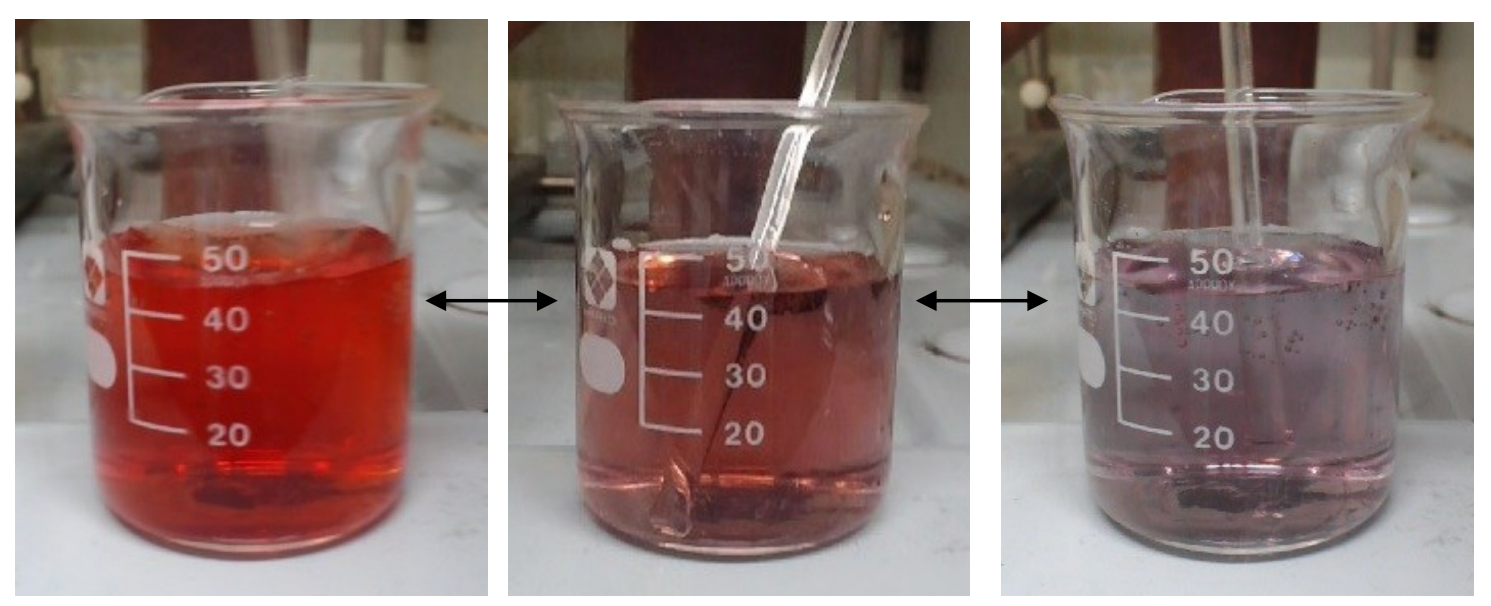

Figure 1. Colour change of BZ reaction solution.

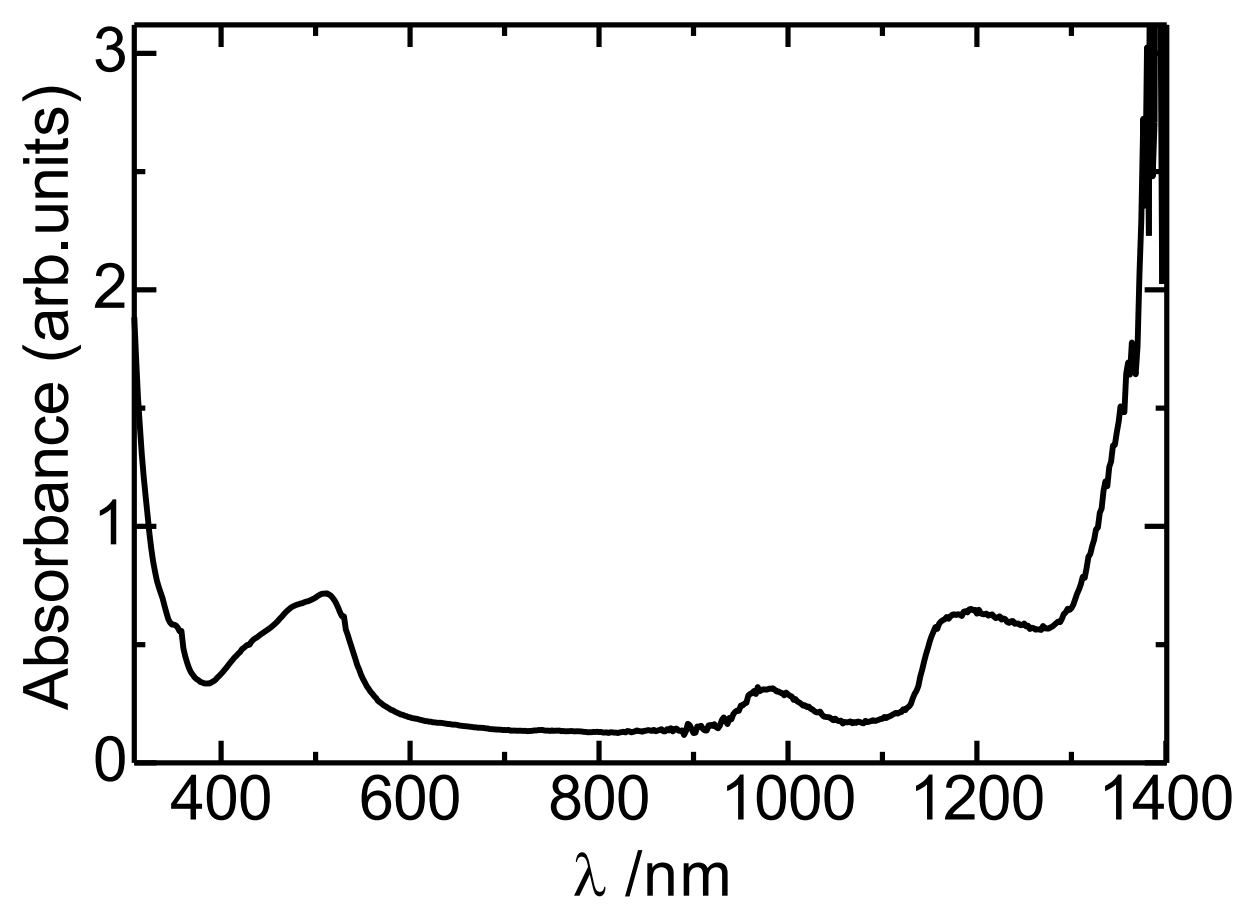

Figure 2. UV-vis spectrum of the BZ reaction solution. 
Figure 2 shows UV-vis NIR optical absorption spectrum of the BZ reaction solution at a certain state. The solution displays optical absorption in the NIR range. Absorption maxima at $510 \mathrm{~nm}, 970 \mathrm{~nm}$, and $1190 \mathrm{~nm}$ were observed. Intensities of the absorptions are changed with time.

Chemical reactions for origin of life and evolution have been explored. The periodical redox reaction may be associated with biological reactions. BZ reaction needs metal complex or ions, although an uncatalyzed oscillatory chemical reaction has been found [2]. In the early stage of chemical evolution on the earth, metal complexes as catalysts can be associated with the reaction. Some of the natural metal complexes from soils or mineral ores [3] may function for synthesis of amino acids.

\section{PERSPECTIVE}

Synthesis of amino acid might be associated with oscillation reactions in the early stage of chemical evolution on the earth. Artificial synthesis of amino acid may be performed in the oscillation system. Consideration of the oscillation reaction in organic synthesis can be reference for chemical evolution in the study of origin of life.

\section{References}

[1] K. Yoshikawa, Non-linear science: Rhythem and form of molecular assembly, Tokyo, 1992, Scientific society (Gakkai) publication centre, (in Japanese).

[2] E. Koros, M. Orban, Nature 273 (1978) 371-372.

[3] H.-P. Bojar, F. Walter, J. Baumgartner, G Färber, Can. Mineral. 48 (2010) 1359-1371. 